\title{
Orbital decompression for thyroid eye disease: surgical treatment outcomes in endocrinological assessment
}

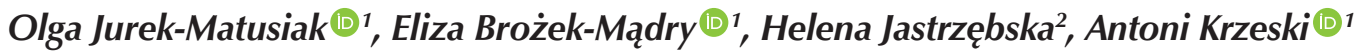 \\ ${ }^{1}$ Department of Otorhinolaryngology, Faculty of Medicine and Dentistry, Medical University of Warsaw, Warsaw, Poland \\ ${ }^{2}$ Department of Endocrinology, Medical Centre of Postgraduate Education in Warsaw, Warsaw, Poland
}

\begin{abstract}
Introduction: Surgical orbital decompression involves removal of one or more of the orbital bony walls in order to gain space for overgrown muscles and adipose tissue, which results in a reduction in pressure on the eye. This observational study aims to perform an endocrinological assessment of the surgical treatment outcomes of thyroid eye disease (TED) patients before and after orbital decompression. Material and methods: This retrospective study included 51 TED patients ( 84 orbits) who underwent endoscopic orbital decompression (EOD) or balanced orbital decompression. The effect of surgical treatment was evaluated via the clinical activity score (CAS), and modified NOSPECS and EUGOGO classification.

Results: Before orbital decompression, the average CAS index was $3.83 \pm 1.86$ points, whereas the modified NOSPECS score was $3.31 \pm$ 0.97 points. After surgical intervention, the values were as follows: $2.07 \pm 1.84$ points for CAS and $2.5 \pm 0.97$ points for modified NOSPECS. The EUGOGO classification before surgery showed that Graves' orbitopathy (GO) was mild, moderate to severe, and sight-threatening in $1 \%, 25 \%$, and $74 \%$ of the orbits, respectively. After surgery, GO was determined to be mild, moderate to severe, and sight-threatening in $24 \%, 57 \%$, and $19 \%$ of the orbits, respectively. Statistical analysis was performed using the R 3.6 .2 statistical environment. Inference about the statistical reliability of the parameter was made by calculating the mean and the $95 \%$ credibility interval (CI).

Conclusions: The severity of TED decreased after orbital decompression. The CAS, and modified NOSPECS and EUGOGO classification showed a statistically reliable postoperative reduction. The drop in activity of the disease after orbital surgery requires careful follow-up. (Endokrynol Pol 2021; 72 (6): 609-617)
\end{abstract}

Key words: thyroid eye disease; orbital decompression; CAS; NOSPECS classification; EUGOGO classification

\section{Introduction}

Thyroid eye disease (TED) is defined as a chronic disease involving the soft tissues of the orbit. The disease is autoimmune, mostly occurring in the course of Graves' disease (90\%) and rarely in Hashimoto's disease (5\%), or in patients without any symptoms of thyroid disease (5\%) [1]. Infiltrative-oedematous changes in the orbit are nowadays found in $10 \%-30 \%$ of patients with Graves' disease, of whom 1\% of patients could turn blind due to optic neuropathy, corneal ulceration, or globe subluxation [2-4]. The criteria for the diagnosis of TED include the presence of inflammation of the orbital soft tissues, proptosis and disturbances in the mobility of the eye, and visual acuity disturbances [1, $3,5]$. TED is considered as a multi-phase disease. In its natural course, an active/inactive phase and plateau can be distinguished. In the first phase, which lasts from several months to several years, the inflammatory process dominates in the soft tissues of the orbit. Meanwhile, the inactive phase is the phase when the disease stabilises and the inflammation is suppressed. However, changes resulting from the fibrosis and scarring of the soft tissues of the orbit will most likely become permanent. In the first year of the disease $65 \%$ of patients experience a spontaneous regression of symptoms resulting from orbital soft tissues; $20 \%$ remain stable, whereas $15 \%$ deteriorate $[2,5-7]$. Care for TED patients is multidisciplinary. The team caring for the patient should include an endocrinologist, ophthalmologist, otorhinolaryngologist, surgeon, maxillofacial surgeon, radiotherapist, and nuclear medicine specialist [1]. Due to the insufficient knowledge about the aetiology of the disease, no causative treatment is available. The treatment is only symptomatic [2] and includes non-surgical or surgical orbital decompression [6]. Non-surgical methods of orbital decompression include glucocorticoid therapy (GCs) or other immunosuppressive pharmacotherapy and orbital radiotherapy (RTH) $[1,3,8]$. Meanwhile, orbital decompression is required when no improvement after conservative treatment is observed. Surgical treatment 
can also be considered as a rehabilitative eye surgery in the inactive phase of the disease [1].

Surgical orbital decompression involves removal of one or more orbital bony walls [3, 9-12]. The main purpose of orbital decompression is to gain space for overgrown muscles and adipose tissue to lower the intraocular pressure, which results in a reduction in pressure on the eye [13]. In principle, each of the four orbital bone walls can be decompressed [14-16]. Currently, the most commonly used type of orbital decompression is endoscopic medial wall decompression and its expansion or inferomedial decompression performed together with the decompression of the lateral wall [17-21]. The main advantages of endoscopic intranasal orbital decompression are as follows: a relatively simple surgical technique, a good insight into the operating field, the ability to assess the content of the orbit, the possibility to accurately control the movement of fat into the nasal cavity, easy identification of the oculomotor muscles, preservation of the physiological drainage path of the paranasal sinuses, and short hospitalisation of the patient. The choice of technique and surgical access depends on the surgeon's experience [19]. Thus, in this study, we aim to investigate the impact of orbital decompression on patients with TED based on the CAS, and the modified NOSPECS and EUGOGO classification.

\section{Material and methods}

This study included a group of 51 patients ( 84 orbits) who were diagnosed with TED and required orbital decompression. Surgery was performed in the Department of Otorhinolaryngology of the Faculty of Medicine and Dentistry, Medical University of Warsaw. The study group consisted of adult patients of both genders (17 men, 34 women), aged 25 to 79 years (average $51.37 \pm 13.24$ years) and hospitalised in the department between 2012 and 2018. Consent from the Bioethics Committee was obtained (KB/69/2018). The inclusion criteria are as follows: (1) a diagnosis of TED, (2) no orbital decompression in the past, (3) available pre- and postoperative ophthalmological examinations, (4) over 18 years of age, and (5) available patient informed consent. Consent was obtained from each patient after a full explanation of the purpose and nature of all procedures used. Meanwhile, the exclusion criteria are as follows: (1) an indication other than TED for orbital surgery, (2) follow-up period less than 3 months, (3) under 18 years of age, and (4) lack of informed consent for the study.

In all patients, the data on preoperative non-surgical treatment was collected: antithyroid drugs, radioiodine treatment, strumectomy, orbital radiotherapy, GCs (IV), and TSH receptor antibodies.

Endocrinological assessment based on the clinical activity score (CAS), and modified NOSPECS and EUGOGO classification was performed:

- preoperatively: in the period ranging from 1 week to 3 months before orbital decompression;

- postoperatively: in the period ranging from 1 week to 3 months after orbital decompression.

For the evaluation of orbital soft tissue symptoms in TED patients, the seven-point CAS classification was used - a tool that measures major clinical symptoms of Graves' orbitopathy (GO) and defines activity of the disease (Supplementary Tab. 1). The range of points in CAS is from 0 to 7. A score of 3 or more indicates active inflammation, while a score of less than 3 indicates the inactive phase. Modified NOSPECS classification (Supplementary Tab. 2) sums up the points obtained in each class (N, O, S, P, E, C, S) $r$ to determine the stage (severity) of the disease. Zero points were given for symptoms in class $\mathrm{N}$. For symptoms assigned to each of the other classes, 1 point was awarded, i.e. a total of 0 to 6 points. The greater the number of points in the NOSPECS classification, the more advanced the disease stage. There are a few modifications in the NOSPECS classification, in which the ophthalmic parameters used for its assessment are changed, the number of assessed parameters is reduced, or the scoring method is different [22-25].

TED severity according to the EUGOGO classification (Supplementary Tab. 3) distinguishes three types of thyroid orbitopathy: mild, severe to moderate, or sight-threatening.

In the case of multi-stage surgical treatment, the final endocrinological assessment is performed after the completion of the surgical treatment. In this study, we assess the effect of the previously applied conservative treatment and the type of selected surgical technique on the results of TED treatment with orbital decompression, according to the selected endocrinological classifications.

\section{Statistical analysis}

Statistical analysis was performed using the R 3.6.2 statistical environment. Hierarchical regression analyses in Bayesian terms were performed using the brms package. Goodness of fit was assessed using LOOIC statistics (leave-one-out information criterion). Inference about the statistical reliability of the parameter was made by calculating the mean and the $95 \%$ credibility interval (CI). Before and after surgical treatment of TED, each eye was assessed using three different endocrinological classifications: CAS, GO severity according to the modified NOSPECS classification, and GO severity according to the EUGOGO classification.

To analyse the effects of the operation (measurement) and covariates, hierarchical ordinal regressions were performed. The selection of this group of analyses resulted from the ordinal nature of the classification: CAS, modified NOSPECS and EUGOGO classification. The scores of these scales are sums of the points measured based on the occurrence of various symptoms. This means that, for example, for two orbits rated at three points on the NOSPECS scale, the symptom set may differ. Because the nature of the scales does not allow for the assumption of equal distances between the values, an analytical method free from such assumption was selected [7]. At the same time, to simplify the presentation of statistical description, the presented statistics were as for quantitative variables. To check whether the changes in the results of CAS, the modified NOSPECS classification, and the EUGOGO classification in TED patients following surgery were statistically reliable and whether the score was related to the covariates included, hierarchical regression analysis was performed for the ordinal data.

\section{Results}

The most common indication for orbital decompression was compressive optic neuropathy $(61 \%, 31 / 51)$, followed by possible vision loss $(31 \%, 16 / 51)$. Poor responders or non-responders to GCs and patients with intolerance to GCs were determined to be less common, with a rate of $4 \%(2 / 51)$ of the cases. Cosmetic indication was noted in a similar number of patients $(4 \%, 2 / 51)$. Treatments used before surgery were as follows: topical treatment, antithyroid drugs, oral or intravenous glucocorticoids, radioiodine, strumectomy, orbital radiotherapy, and alternative management (e.g. immunoglobulins, etc.). Therapies overlapped in most cases. 
An effective medical procedure was performed in one stage in 32 patients (57 orbits). In the absence of improvement after the surgical treatment, 16 patients $(24$ orbits) underwent the next stage of treatment (extension of the orbital decompression range), and 3 patients ( 3 orbits) underwent the 3 stages of treatment. The overall rate of postoperative complications was $15.47 \%$. We observed sinonasal and orbital complications, where the most common was facial hypoaesthesia of the trigeminal nerve branch innervation (5\%).

The changes in the results of individual classifications are presented below:

\section{CAS}

Before surgery, the mean value of the CAS was $3.83 \pm 1.86$ points (values ranged between 0 and 7 points). After surgery, the CAS mean value was $2.07 \pm 1.84$ points (range $0-7$ points) regardless of the surgical approach used. At the descriptive level, after the surgical treatment, lower average values of the CAS were recorded. Before surgery, 65 out of
84 orbits $(77 \%)$ were found to be in the active phase of the disease, and 28 orbits $(33 \%)$ were found to be in the active phase of the disease after surgery. The outcomes of the operation according to the CAS classification indicated an improvement in 59 orbits $(70 \%)$, deterioration in 7 orbits $(9 \%)$, and no change in 18 orbits $(21 \%)$.

The results with regard to surgical access used in the studied group of 51 patients were as follows:

- before medial wall decompression $(n=52)$ - mean value $3.69 \pm 1.86$; after medial wall decompression - mean value $1.87 \pm 1.75$;

- before inferomedial wall decompression $(\mathrm{n}=12)$ - mean value $3.92 \pm 1.24$; after inferomedial wall decompression - mean value $1.92 \pm 1.92$;

- before mediolateral wall decompression $(n=20)$ - mean value $4.15 \pm 2.18$; after mediolateral wall decompression - mean value $2.7 \pm 1.87$.

Table 1 shows a summary of the posterior distributions of the parameters for the full statistical model. It was noted that the measurement model was the best

Table 1. The results of the hierarchical ordinal regression analysis with the results of the Clinical Activity Score classification as a dependent variable

\begin{tabular}{|c|c|c|c|c|c|}
\hline \multirow{2}{*}{\multicolumn{2}{|c|}{$\begin{array}{l}\text { DV: CAS } \\
\text { Parameter }\end{array}$}} & \multirow[b]{2}{*}{ M } & \multirow[b]{2}{*}{ SE } & \multicolumn{2}{|c|}{$95 \% \mathrm{Cl}$} \\
\hline & & & & LI & UI \\
\hline \multirow{17}{*}{$\beta$} & Constant [1] & -1.85 & 0.51 & -2.87 & -0.91 \\
\hline & Constant [2] & -0.81 & 0.46 & -1.76 & 0.07 \\
\hline & Constant [3] & -0.31 & 0.43 & -1.2 & 0.56 \\
\hline & Constant [4] & 0.73 & 0.45 & -0.16 & 1.6 \\
\hline & Constant [5] & 0.99 & 0.48 & 0.03 & 1.95 \\
\hline & Constant [6] & 2.45 & 0.55 & 1.41 & 3.62 \\
\hline & Constant [7] & 2.8 & 0.75 & 1.42 & 4.29 \\
\hline & Measurement & -0.82 & 0.12 & -1.07 & -0.6 \\
\hline & Orbit & 0.04 & 0.09 & -0.13 & 0.21 \\
\hline & Decompression [1] ${ }^{*}$ & -0.15 & 0.2 & -0.55 & 0.25 \\
\hline & Decompression [2] & -0.09 & 0.32 & -0.7 & 0.52 \\
\hline & Antithyroid drugs & 0.01 & 0.22 & -0.41 & 0.45 \\
\hline & Radioiodine & 0.35 & 0.24 & -0.11 & 0.85 \\
\hline & Strumectomy & 0.14 & 0.27 & -0.34 & 0.71 \\
\hline & Orbital radiotherapy & -0.3 & 0.28 & -0.9 & 0.23 \\
\hline & TRAb concentration & 0.03 & 0.02 & 0 & 0.07 \\
\hline & GCs IV (total dose) & 0.12 & 0.08 & -0.03 & 0.27 \\
\hline$\tau$ & Constant & 1.38 & 0.26 & 0.92 & 1.95 \\
\hline \multicolumn{2}{|c|}{ Comparison of models } & $\Delta \mathrm{LOOIC}$ & SE & & \\
\hline \multicolumn{2}{|c|}{ Measurement null } & -92.95 & 14.09 & & \\
\hline \multicolumn{2}{|c|}{ Full measurement } & 5.95 & 4.95 & & \\
\hline
\end{tabular}

Constants 1-7 are the estimated distances between the CAS levels on a latent score; DV — dependent variable; $\mathrm{Cl}$ — credibility interval; $\mathrm{M}$ — median; SE — standard error; LI/UI — lower/upper interval; $\beta$ - regression coefficients; $\tau$ — standard deviation of individual constant values $(\beta) ;{ }^{*}$ - nominal variables 


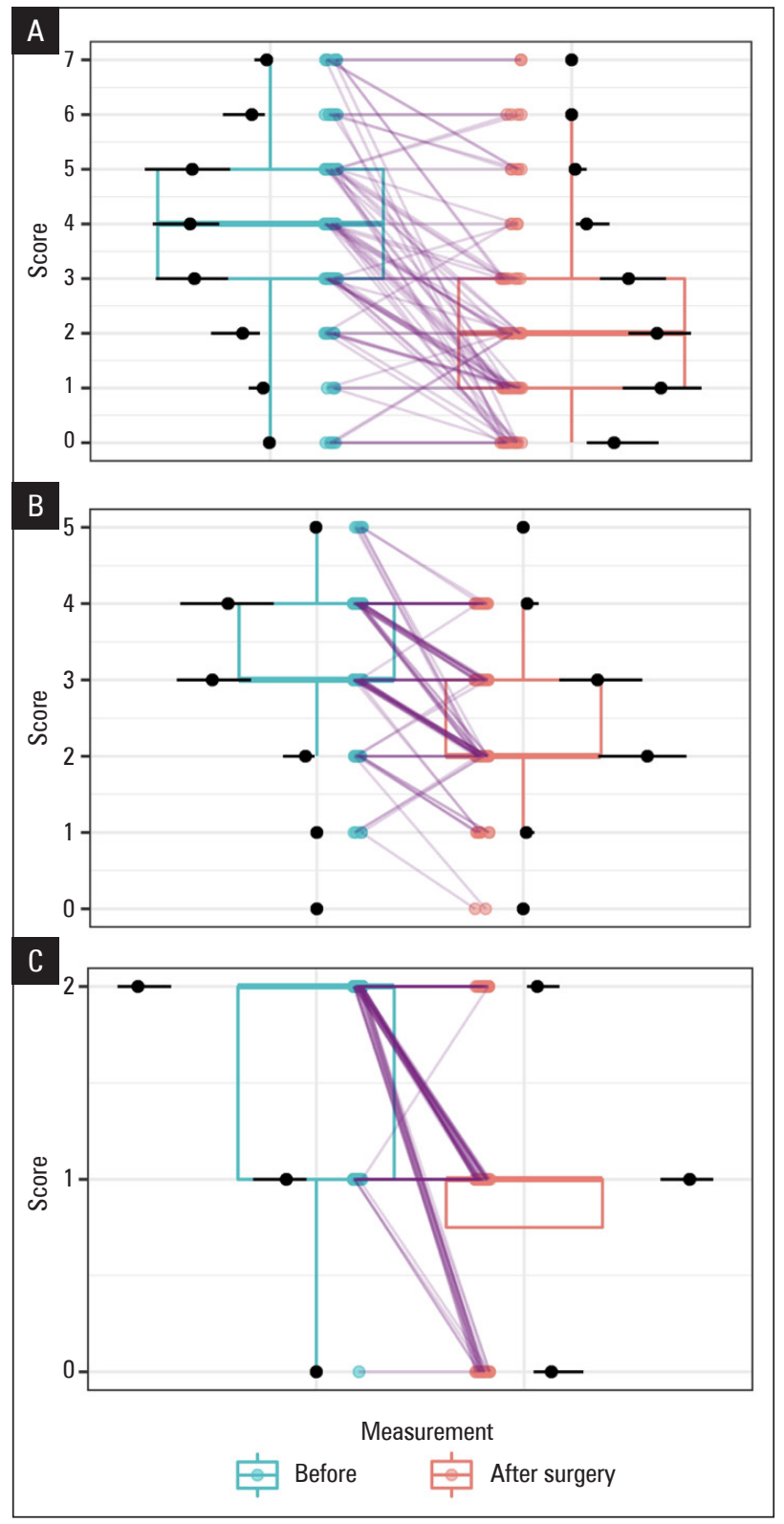

Figure 1A-C. Results of the CAS (A), modified NOSPECS (B), and EUGOGO (C) classification before and after orbital decompression. Box plots show the distribution of individual values. Points connected by purple lines are pairs of observations for the same orbit. The black points show the estimated marginal probabilities for a given value of each score (CAS, NOSPECS, EUGOGO) at a given time of measurement. The horizontal black lines are the 95\% credibility intervals for the probability estimation

fit to the data and the measurement effect coefficient was statistically reliable. This means that the results for CAS have plausibly changed statistically but were not covariant dependent.

It was noted that the score obtained in the CAS classification was lower than that before the operation. Before orbital decompression, the most common scores were values of 3,4 , and 5 , whereas after surgery, the most common values were 1,2 , and 3 (Fig. 1A).

\section{GO severity according to the modified NOSPECS classification}

The mean value of the modified NOSPECS classification before orbital decompression was $3.31 \pm 0.97$ points (results ranged from 1 to 5 points). These measurements changed to $2.5 \pm 0.97$ points (results ranged from 0 to 4 points) after orbital decompression regardless of the surgical approach used.

At the descriptive level, lower average modified NOSPECS classification scores after surgery were obtained. The surgery resulted in better modified NOSPECS classification scores (lower score) for 55 orbits $(65 \%)$, worse scores (higher score) for 6 orbits (7\%), and the same scores for 23 orbits $(27 \%)$.

The results with regard to surgical access used in the studied group of 51 patients ( $n=84$ orbits) were as follows:

- before medial wall decompression $(n=52)$ - mean value $3.23 \pm 1.04$; after medial wall decompression - mean value $2.29 \pm 1.00$;

- before inferomedial wall decompression $(n=12)$ - mean value $3.75 \pm 0.45$; after inferomedial wall decompression - mean value $2.92 \pm 0.79$;

- before mediolateral wall decompression $(n=20)$ - mean value $3.25 \pm 0.97$; after mediolateral wall decompression - mean value $2.8 \pm 0.83$.

Table 2 shows a summary of the posterior distributions of the parameters for the full statistical model. It was noted that the measurement model was the best fit for the data and the measurement effect coefficient was statistically reliable. This indicates that the results obtained in the modified NOSPECS classification changed statistically reliably but were not dependent on the covariates.

The modified NOSPECS classification results were lower after surgery. Before surgery, the most common severity scores were values of 3 and 4 , whereas after surgery, the most common values were 2 and 3 (Fig. 1B).

\section{GO severity according to the EUGOGO classification}

Before surgery, mild GO occurred in 1 orbit $(1 \%)$, moderate to severe GO in 21 orbits $(25 \%)$ and sight-threatening GO in 62 orbits (74\%).

After orbital decompression, lower average results in the EUGOGO classification were reported: mild GO was observed in 20 orbits (24\%), moderate to severe GO in 48 orbits (57\%), and sight-threatening GO in 16 orbits (19\%). The surgery outcomes indicated deterioration in 1 orbit $(1 \%)$, improvement in 49 orbits $(58 \%)$, and no change in 34 orbits $(40 \%)$. The results with regard to surgical access used in the studied group of 51 patients ( $\mathrm{n}=84$ orbits) were as follows: 
Table 2. The results of the hierarchical ordinal regression analysis with the results of the modified NOSPECS classification as the dependent variable

\begin{tabular}{|c|c|c|c|c|c|}
\hline \multirow{2}{*}{\multicolumn{2}{|c|}{$\begin{array}{l}\text { DV: modified NOSPECS classification } \\
\text { Parameter }\end{array}$}} & \multirow[b]{2}{*}{ M } & \multirow[b]{2}{*}{ SE } & \multicolumn{2}{|c|}{$95 \% \mathrm{Cl}$} \\
\hline & & & & LI & UI \\
\hline \multirow{15}{*}{$\beta$} & Constant [1] & -8.76 & 1.66 & -12.2 & -5.82 \\
\hline & Constant [2] & -5.41 & 1.04 & -7.59 & -3.45 \\
\hline & Constant [3] & -0.68 & 0.78 & -2.27 & 0.92 \\
\hline & Constant [4] & 2.16 & 0.82 & 0.68 & 3.83 \\
\hline & Constant [5] & 7.26 & 1.19 & 5.17 & 9.72 \\
\hline & Measurement & -1.56 & 0.24 & -2.04 & -1.13 \\
\hline & Orbit* & 0.08 & 0.17 & -0.27 & 0.42 \\
\hline & Decompression [1] ${ }^{*}$ & -0.31 & 0.48 & -1.27 & 0.62 \\
\hline & Decompression [2] ${ }^{*}$ & 0.51 & 0.68 & -0.83 & 1.85 \\
\hline & Antithyroid drugs & 0.03 & 0.49 & -0.95 & 0.98 \\
\hline & Radioiodine & 0.21 & 0.55 & -0.88 & 1.31 \\
\hline & Strumectomy & 0.53 & 0.59 & -0.61 & 1.68 \\
\hline & Orbital radiotherapy & 0.26 & 0.64 & -0.96 & 1.54 \\
\hline & TRAb & 0.06 & 0.04 & -0.02 & 0.15 \\
\hline & GCs IV - total dose & -0.15 & 0.17 & -0.49 & 0.19 \\
\hline$\tau$ & Constant & 3.18 & 0.56 & 2.18 & 4.42 \\
\hline \multicolumn{2}{|c|}{ Comparison of models } & LOOIC & SE & & \\
\hline \multicolumn{2}{|c|}{ Measurement null } & -82.74 & 16.19 & & \\
\hline \multicolumn{2}{|c|}{ Full measurement } & 6.01 & 3.24 & & \\
\hline
\end{tabular}

Constants 1-5 are the estimated distances between modified NOSPECS levels on a latent scale; DV — dependent variable; $\mathrm{Cl}$ — credibility interval; $\mathrm{M}$ - median; SE — standard error; LI/UI — lower /upper interval; $\beta$ — regression coefficients; $\tau$ — standard deviation of individual constant values $(\beta) ;{ }^{*}$ - nominal variables

- before medial wall decompression $(n=52)$ - mild GO -1 orbit $(2 \%)$, moderate to severe GO - 16 orbits (31\%), and sight-threatening GO - 35 orbits (67\%); after medial wall decompression — mild GO - 13 orbits $(25 \%)$, moderate to severe $\mathrm{GO}-32$ orbits (62\%), and sight-threatening GO -7 orbits $(13 \%)$;

- before inferomedial wall decompression $(n=12)$

- mild and moderate to severe GO - 0 orbits, and sight-threatening GO - 12 orbits (100\%); after inferomedial wall decompression - mild GO -2 orbits $(17 \%)$, moderate to severe $\mathrm{GO}-7$ orbits (66\%), and sight-threatening $\mathrm{GO}-2$ orbits $(17 \%)$

Before mediolateral wall decompression $(n=20)$ - mild GO - 0 orbits ( $2 \%)$, moderate to severe GO -5 orbits $(25 \%)$, and sight-threatening GO -16 orbits (75\%); after mediolateral wall decompression - mild $\mathrm{GO}-5$ orbits $(25 \%)$, moderate to severe $\mathrm{GO}-9$ orbits $(45 \%)$, and sight-threatening GO -7 orbits $(35 \%)$.

Table 3 shows a summary of the posterior distributions of the parameters for the full statistical model. It should be noted that the measurement model was the best fit for the data and the measurement effect coefficient was statistically reliable. This means that the results of the EUGOGO classification changed statistically credibly but were not dependent on covariates. As expected, the EUGOGO scores were lower after surgery. Before surgery the most common point score was 2 (vision-threatening form), whereas after surgery the dominant value was 1 (moderate to severe form) (Fig. 1C). Table 4 shows the summary of the results in the endocrinological classifications before and after orbital decompression.

The statistical analysis of the examined ophthalmic parameters in relation to covariates showed the following:

- the results for the CAS, modified NOSPECS, and EUGOGO classification changed statistically reliably but were not covariant dependent. All scores were lower after orbital decompression;

- the results of endocrinological parameters did not change in a statistically reliable manner depending on the type of decompression applied;

- no statistically reliable changes were observed in the results of the endocrinological parameters in correlation with the type of previously used non-surgical treatment of thyroid orbitopathy. 
Table 3. The results of the hierarchical ordinal regression analysis with the results of the EUGOGO classification as the dependent variable

\begin{tabular}{|c|c|c|c|c|c|}
\hline \multirow{2}{*}{\multicolumn{2}{|c|}{$\begin{array}{l}\text { DV: EUGOGO classification } \\
\text { Parameter }\end{array}$}} & \multirow[b]{2}{*}{ M } & \multirow[b]{2}{*}{ SE } & \multicolumn{2}{|c|}{$95 \% \mathrm{Cl}$} \\
\hline & & & & LI & UI \\
\hline \multirow{12}{*}{$\beta$} & Constant [1] & -5.26 & 1.21 & -7.98 & -3.28 \\
\hline & Constant [2] & 0.3 & 0.82 & -1.31 & 1.92 \\
\hline & Measurement & -2.73 & 0.52 & -3.85 & -1.86 \\
\hline & Orbit* & -0.02 & 0.24 & -0.49 & 0.43 \\
\hline & Decompression [1] & -0.37 & 0.54 & -1.42 & 0.7 \\
\hline & Decompression [2] ${ }^{*}$ & 0.21 & 0.82 & -1.34 & 1.9 \\
\hline & Antithyroid drugs & 0.41 & 0.57 & -0.67 & 1.64 \\
\hline & Radioiodine & -0.37 & 0.6 & -1.59 & 0.76 \\
\hline & Strumectomy & 1.17 & 0.68 & -0.05 & 2.69 \\
\hline & Orbital radiotherapy & -0.82 & 0.72 & -2.35 & 0.61 \\
\hline & TRAb & 0.08 & 0.05 & -0.01 & 0.18 \\
\hline & GCs IV - total dose & -0.08 & 0.18 & -0.45 & 0.27 \\
\hline$\tau$ & Constant & 3.28 & 0.81 & 1.95 & 5.08 \\
\hline \multicolumn{2}{|c|}{ Comparison of models } & $\Delta \mathrm{LOOIC}$ & SE & & \\
\hline \multicolumn{2}{|c|}{ Measurement null } & -101.05 & 14.98 & & \\
\hline \multicolumn{2}{|c|}{ Full measurement } & 6.82 & 5.54 & & \\
\hline
\end{tabular}

Constants [1-2] are the estimated distances between EUGOGO levels on a latent scale; DV — dependent variable; $\mathrm{Cl}$ — credibility interval; $\mathrm{M}$ — median; $\mathrm{SE}$ - standard error; L//UI — lower/upper interval; $\beta$ - regression coefficients; $\tau$ — standard deviation of individual constant values $(\beta) ;{ }^{*}$ — nominal variables

Table 4. Endocrine classification results before and after orbital decompression $(n=84)$

\begin{tabular}{|c|c|c|c|c|c|c|c|c|c|c|}
\hline \multirow{2}{*}{\multicolumn{2}{|c|}{ Before orbital decompression }} & \multirow[b]{3}{*}{$\%$} & \multicolumn{8}{|c|}{ After orbital decompression } \\
\hline & & & \multicolumn{2}{|c|}{ Total } & \multicolumn{2}{|c|}{ Improvement } & \multicolumn{2}{|c|}{ No changes } & \multicolumn{2}{|c|}{ Worsened } \\
\hline $\begin{array}{l}\text { Endocrinological } \\
\text { classification }\end{array}$ & $\begin{array}{c}\text { No. of } \\
\text { orbits } \\
(n=84)\end{array}$ & & $\begin{array}{l}\text { No. of } \\
\text { orbits }\end{array}$ & $\%$ & $\begin{array}{l}\text { No. of } \\
\text { orbits }\end{array}$ & $\%$ & $\begin{array}{l}\text { No. of } \\
\text { orbits }\end{array}$ & $\%$ & $\begin{array}{l}\text { No. of } \\
\text { orbits }\end{array}$ & $\%$ \\
\hline \multicolumn{11}{|c|}{ Clinical activity score (type) } \\
\hline Active & 65 & 76 & 28 & 33 & 59 & 91 & 6 & 7 & 0 & 0 \\
\hline Non-active & 19 & 24 & 56 & 67 & 0 & 0 & 12 & 63 & 7 & 37 \\
\hline \multicolumn{11}{|c|}{ GO severity according to the modified NOSPECS classification (points) } \\
\hline 0 & 0 & 0 & 2 & 2 & 0 & 0 & 0 & 0 & 0 & 0 \\
\hline 1 & 4 & 5 & 7 & 8 & 1 & 25 & 0 & 0 & 3 & 75 \\
\hline 2 & 13 & 15 & 39 & 46 & 6 & 46 & 5 & 38 & 2 & 16 \\
\hline 3 & 28 & 33 & 22 & 26 & 20 & 71 & 7 & 25 & 1 & 4 \\
\hline 4 & 33 & 40 & 14 & 17 & 22 & 65 & 11 & 35 & 0 & 0 \\
\hline 5 & 6 & 7 & 0 & 0 & 6 & 100 & 0 & 0 & 0 & 0 \\
\hline 6 & 0 & 0 & 0 & 0 & 0 & 0 & 0 & 0 & 0 & 0 \\
\hline \multicolumn{11}{|c|}{ GO severity according to the EUGOGO classification (type) } \\
\hline Mild & 1 & 1 & 5 & 6 & 0 & 0 & 1 & 100 & 0 & 0 \\
\hline Moderate to severe & 20 & 25 & 61 & 73 & 4 & 20 & 15 & 75 & 1 & 5 \\
\hline Sight-threatening & 63 & 74 & 18 & 21 & 45 & 71 & 18 & 29 & 0 & 0 \\
\hline
\end{tabular}


- better results in terms of applied classifications were observed in the active phase/more severe stage of the disease.

\section{Discussion}

Only a few studies available in the literature (2010-2020) investigated the outcomes of TED treatment with orbital decompression based on the endocrinological scores/classifications. Many classifications are used to assess the activity and severity of thyroid orbitopathy. These scales are used more often by endocrinologists than by orbital surgeons, and their results are discussed in studies on treatment. Research into the surgical treatment of TED usually excludes the changes assessed using endocrine classifications. There are a few modifications in the NOSPECS classification, in which the ophthalmic parameters used for its assessment are altered, the number of assessed parameters is reduced, or the scoring method is different [22-25]

Jefferis et al. discussed the results of the treatment of 55 patients (93 orbits) who underwent orbital decompression. In their studies, they presented data on the mean preoperative CAS, which was $1.4 \pm 2.0$ points before surgery. In the active phase of the disease the patients scored an average of $3.9 \pm 2.5$ points, whereas in the inactive phase they reportedly scored $0.9 \pm 1.4$ points. The authors did not evaluate the patients after surgical intervention [26].

Lal et al. presented the results of endoscopic medial wall decompression in 12 patients (24 orbits). In the preoperative assessment, they used the NOSPECS classification and a 10-point CAS classification. Based on the NOSPECS classification, 7 patients (58\%) qualified for stage III of GO, 2 patients (17\%) for stage IV, 1 patient $(8 \%)$ for grade $\mathrm{V}$, and 2 patients $(17 \%)$ for up to grade VI classification. Meanwhile, as per the CAS classification, 11 patients $(92 \%)$ were in the inactive phase of the disease, whereas 1 patient $(8 \%)$ was in the active phase of the disease. Moreover, Lal et al. analysed the results of endoscopic decompression of the medial wall of the orbit in 12 patients ( 24 orbits). The authors did not assess the study group using these classifications after performing surgery [27].

Oh et al. also analysed the results of treatment after maximal lateral wall decompression with adipose tissue removal in 24 patients (31 orbits). They assessed the patients before and after surgery using the CAS classification. Before orbital decompression, the mean CAS for the operated orbits was $9.5 \pm 0.4$ points. Six months after the surgical treatment, this index was $2.9 \pm 0.4$ points, and after a year it was $2.1 \pm 0.6$ points $(p<0.01)$. For non-operated contralateral orbits, the result was $7.4 \pm 0.3$ points before the surgery, $3.5 \pm 0.1$ points after the first 6 months, and $3.2 \pm 0.5$ points 1 year after the surgery $(p<0.05)[28]$.

Miśkiewicz et al. reported the results of the treatment of 10 patients (18 orbits) with dysthyroid neuropathy treated with endoscopic medial wall decompression and high doses of GCs. They assessed the patients using the CAS classification. Before surgery, they recorded a CAS mean value of 4 (range 2-6 points) and a CAS point reduction from 4 to 2 points (range $0-3$ points) after treatment [29].

In our group of TED patients treated with orbital decompression, the results of the 7-point CAS classification showed that before the surgery, $76 \%$ of the orbits were in the active phase of the disease $(>3$ points), whereas $24 \%$ were determined to be in the inactive phase ( $\leq 3$ points). Before surgery, the mean value of CAS was $3.83 \pm 1.86$ points (range $0-7$ points), and after surgery, the mean value was $2.07 \pm 1.84$ points (range $0-7$ points) regardless of the surgical technique used. In the pre- and postoperative CAS analysis, better results were observed in patients with the active phase of the disease. This observational study is valuable because most articles address the surgical treatment in the inactive phase of disease. However, one limitation of this observational study is the smaller group of inactive TED patients (19 inactive vs. 65 active orbits). Similarly, based on the NOSPECS classification, those patients that worsened had lower results preoperatively, but the group was small. The most common values in the NOSPECS classification before surgery were 3 and 4, whereas after surgery, the most common values were 2 and 3 . The weak point of this paper was that we only had the possibility to classify the patients in NOSPECS as class 0-6 without determining the degree of severity in each class. In the EUGOGO classification, the best results were observed in a group of patients with sight-threatening disease, whereas no changes were observed in the moderate to severe (20) and mild (1) patients.

The Bayesian statistical analysis showed that postoperative changes in the CAS classification, modified NOSPECS classification and the transition from a higher to a lower severity of EUGOGO classification were statistically reliable.

When analysing those results, it should be emphasised that this paper, in contrast to other papers, presents a majority of patients operated in the active form of the disease $(76 \%)$. The endocrinological classifications have been determined to be very helpful in the GO patients' assessment, but they should be utilised consciously. Surgical decompression does not change the patients' endocrine status, and even though the patients reach the inactive phase after orbital decompression according to CAS, they should be carefully followed 
by a group of specialists in this field. Those results lead to the question of whether we should change the scoring system of activity of the disease or whether these scoring systems should indicate that the patient was assessed after surgery.

Thirteen patients underwent a postoperative examination less than one month after the surgical intervention, and the rest more than one month after the surgical intervention. The initial comparison of the groups shows better results (lower scores obtained in the classifications) in patients with a follow-up examination longer than a month. Due to the small size of the groups, it is difficult to analyse them statistically. This observation may be explained by the fact that postoperative healing usually takes 3-4 weeks. More research is needed to assess the impact of time since surgery on the results of endocrine classifications.

\section{Conclusions}

Based on the analysis of the results obtained, it can be concluded that orbital decompression is an effective treatment method in patients with TED. Even though the surgical decompression in TED may become less relevant due to the development in pharmacotherapy - especially in biological treatment, it can still be considered as the tool for non-responders to pharmacological decompression. Orbital decompression results in an improvement in endocrinological assessment with commonly used classifications.

\section{Funding}

This research did not receive any specific grant from funding agencies in the public, commercial, or not-for-profit sectors.

\section{Data sharing and availability statement}

Data available on request from the authors.

\section{Conflict of interest}

None.

\section{References}

1. Bednarczuk T, Bar-Andziak E, Hubalewska-Dydejczyk A, et al. [Management of Graves' orbitopathy. Comments on the EUGOGO consensus statement]. Endokrynol Pol. 2009; 60(4): 312-330, indexed in Pubmed: 19753546.

2. Tanda ML, Piantanida E, Liparulo L, et al. Prevalence and natural history of Graves' orbitopathy in a large series of patients with newly diagnosed graves' hyperthyroidism seen at a single center. J Clin Endocrinol Metab. 2013; 98(4): 1443-1449, doi: 10.1210/jc.2012-3873, indexed in Pubmed: 23408569.

3. Bartalena L, Baldeschi L, Boboridis K, et al. European Group on Graves' Orbitopathy (EUGOGO). The 2016 European Thyroid Association/European Group on Graves' Orbitopathy Guidelines for the Management of Graves' Orbitopathy. Eur Thyroid J. 2016; 5(1): 9-26, doi: 10.1159/000443828, indexed in Pubmed: 27099835.

4. Ackuaku-Dogbe EM, Akpalu J, Abaidoo B. Epidemiology and Clinical Features of Thyroid-associated Orbitopathy in Accra. Middle East Afr
J Ophthalmol. 2017; 24(4): 183-189, doi: 10.4103/meajo.MEAJO_91_17, indexed in Pubmed: 29422752

5. Szczeklik A. Choroby wewnętrzne. 1 ed. Medycyna Praktyczna, Krakow 2005.

6. Zgliczyński S, Jastrzebska H, Górowski T, et al. [Results of 3-stage treatment: (I) corticotherapy, (II) linear acceleration and (III) orbital decompression in 206 patients with malignant Graves ophthalmopathy]. Endokrynol Pol. 1992; 43(3): 274-286, indexed in Pubmed: 1345567.

7. Sabini E, Ionni I, Rocchi R, et al. Occurrence of Graves' Orbitopathy and Graves' Hyperthyroidism after a Trauma to the Eye. Eur Thyroid J. 2018; 7(1): 51-54, doi: 10.1159/000479629, indexed in Pubmed: 29594055.

8. Wang Y, Zhou H, Fan X. The effect of orbital radiation therapy on thyroid-associated orbitopathy complicated with dysthyroid optic neuropathy. Front Med. 2017; 11(3): 359-364, doi: 10.1007/s11684-017-0528-5, indexed in Pubmed: 28500433.

9. Sellari-Franceschini S, Rocchi R, Marinò M, et al. Rehabilitative orbital decompression for Graves' orbitopathy: results of a randomized clinical trial. J Endocrinol Invest. 2018; 41(9): 1037-1042, doi: 10.1007/s40618-018-0847-7, indexed in Pubmed: 29450866.

10. Eckstein A, Esser J, Oeverhaus M, et al. Surgical Treatment of Diplopia in Graves Orbitopathy Patients. Ophthalmic Plast Reconstr Surg. 2018; 34(4S Suppl 1): S75-S84, doi: 10.1097/IOP.0000000000001148, indexed in Pubmed: 29905641.

11. Seibel I, Hofmann VM, Sönmez H, et al. Medial and mediolateral orbital decompression in intractable Graves' Orbitopathy. Auris Nasus Larynx. 2017; 44(4): 428-434, doi: 10.1016/j.anl.2016.08.007, indexed in Pubmed: 27609530

12. Hernández-García E, San-Román JJ, González R, et al. Balanced (endoscopic medial and transcutaneous lateral) orbital decompression in Graves' orbitopathy. Acta Otolaryngol. 2017; 137(11): 1183-1187, doi: 1 0.1080/00016489.2017.1354394, indexed in Pubmed: 28741406.

13. Alsuhaibani AH, Nerad JA. Thyroid-associated orbitopathy. Semin Plast Surg. 2007; 21(1): 65-73, doi: 10.1055/s-2007-967751, indexed in Pubmed: 20567660

14. Kalmann R, Mourits MP, van der Pol JP, et al. Coronal approach for rehabilitative orbital decompression in Graves' ophthalmopathy. $\mathrm{Br}$ J Ophthalmol. 1997; 81(1): 41-45, doi: 10.1136/bjo.81.1.41, indexed in Pubmed: 9135407.

15. Leong SC, Karkos PD, Macewen CJ, et al. A systematic review of outcomes following surgical decompression for dysthyroid orbitopathy. Laryngoscope. 2009; 119(6): 1106-1115, doi: 10.1002/lary.20213, indexed in Pubmed: 19358198.

16. West M, Stranc M. Long-term results of four-wall orbital decompression for Graves' ophthalmopathy. Br J Plast Surg. 1997; 50(7): 507-516, doi: 10.1016/s0007-1226(97)91299-6, indexed in Pubmed: 9422948.

17. Wu CY, Niziol LM, Musch DC, et al. Thyroid-Related Orbital Decompression Surgery: A Multivariate Analysis of Risk Factors and Outcomes. Ophthalmic Plast Reconstr Surg. 2017; 33(3): 189-195, doi: 10.1097/IOP.0000000000000699, indexed in Pubmed: 27097064.

18. Wu T, Tang DR, Wang F, et al. [Multi-wall orbital decompression for disfiguring proptosis in patients with mild or moderate thyroid eye disease]. Zhonghua Yan Ke Za Zhi. 2017; 53(2): 128-135, doi: 10.3760/cm a.j.issn.0412-4081.2017.02.011, indexed in Pubmed: 28260364.

19. Rootman DB. Orbital decompression for thyroid eye disease. Surv Ophthalmol. 2018; 63(1): 86-104, doi: 10.1016/j.survophthal.2017.03.007, indexed in Pubmed: 28343872.

20. Dharmasena A, Keenan TDL, Goldacre MJ. Orbital decompression for thyroid-associated orbitopathy in England: trends over time and geographical variation. Orbit. 2014; 33(2): 109-114, doi: 10.3109/016768 30.2013.851707, indexed in Pubmed: 24295168.

21. Ediriwickrema LS, Korn BS, Kikkawa DO. Orbital Decompression for Thyroid-Related Orbitopathy During the Quiescent Phase. Ophthalmic Plast Reconstr Surg. 2018; 34(4S Suppl 1): S90-S97, doi: 10.1097/IOP.0000000000001119, indexed in Pubmed: 29771754.

22. Woo YJ, Jang SY, Lim TH, et al. Clinical Association of Thyroid Stimulating Hormone Receptor Antibody Levels with Disease Severity in the Chronic Inactive Stage of Graves' Orbitopathy. Korean J Ophthalmol. 2015; 29(4): 213-219, doi: 10.3341/kjo.2015.29.4.213, indexed in Pubmed: 26240504

23. Woo YJ, Kim JW, Yoon JS. Preoperative clinical features of reactivated of Graves' orbitopathy after orbital decompression. Eye (Lond). 2017; 31(4): 643-649, doi: 10.1038/eye.2016.304, indexed in Pubmed: 28060361.

24. Lee H, Lee $\mathrm{YH}$, Suh SI, et al. Characterizing Intraorbital Optic Nerve Changes on Diffusion Tensor Imaging in Thyroid Eye Disease Before Dysthyroid Optic Neuropathy. J Comput Assist Tomogr. 2018; 42(2): 293-298, doi: 10.1097/RCT.0000000000000680, indexed in Pubmed: 28937496

25. Profilo MA, Sisti E, Marcocci C, et al. Thyroid volume and severity of Graves' orbitopathy. Thyroid. 2013; 23(1): 97-102, doi: 10.1089/thy.2012.0379, indexed in Pubmed: 23088654. 
26. Jefferis JM, Jones RK, Currie ZI, et al. Orbital decompression for thyroid eye disease: methods, outcomes, and complications. Eye (Lond). 2018; 32(3): 626-636, doi: 10.1038/eye.2017.260, indexed in Pubmed: 29243735.

27. Lal P, Thakar A, Tandon N. Endoscopic orbital decompression for Graves' orbitopathy. Indian J Endocrinol Metab. 2013; 17(2): 265-270, doi: 10.4103/2230-8210.109707, indexed in Pubmed: 23776900
28. Oh SR, Tung JD, Priel A, et al. Reduction of orbital inflammation following decompression for thyroid-related orbitopathy. Biomed Res Int. 2013; 2013: 794984, doi: 10.1155/2013/794984, indexed in Pubmed: 23853771.

29. Miśkiewicz P, Rutkowska B, Jabłońska A, et al. Complete recovery of visual acuity as the main goal of treatment in patients with dysthyroid optic neuropathy. Endokrynol Pol. 2016; 67(2): 166-173, doi: 10.5603/EP.a2016.0018, indexed in Pubmed: 26884288. 